\title{
Arte y poesía en Cura Malal: un corral de piedras donde el paisaje y la comunidad resisten
}

\author{
ART AND POETRY IN CURA MALAL: A STONE CORRAL WHERE THE LANDSCAPE \\ AND THE COMMUNITY RESIST
}

\section{ARTE E POESIA EM CURA MALAL: UM CURRAL DE PEDRA ONDE A PAISAGEM E A COMUNIDADE RESISTEM}

\author{
María Eugenia Rasic *1 \\ mariaeugeniarasic@gmail.com
}

\section{Resumen}

A partir de las acciones artísticas, poéticas, archivísticas y, fundamentalmente, colectivas impulsadas por las integrantes del Proyecto Hermosura en el territorio de Cura Malal, provincia de Buenos Aires, Argentina, y, a su vez, a partir de la obra visual y arqueológica de una de sus integrantes y habitantes del lugar, Mercedes Resch, será posible leer en este artículo dos importantes movimientos. Por un lado, los procesos de modernización y de transformación histórica en la comunidad y en el paisaje rural-serrano de Cura Malal. Por otro lado, los procesos de recuperación y de preservación de un sentido de comunidad y de paisaje que dichas transformaciones históricas han dejado como ruinas pero que, al mismo tiempo, emergen como fuerzas latentes cuando posamos nuestro interés crítico sobre ellas. El arte y la poesía serán, de este modo, acciones individuales y colectivas capaces de visibilizar y hacer sonar esas supervivencias, así como también resguardar a la comunidad de Cura Malal y a su entorno natural de la desaparición.

Palabras clave: arte y poesía, Cura Malal, Mercedes Resch, paisaje, Proyecto Hermosura

\footnotetext{
Abstract

From the artistic, poetic, archival and, fundamentally, collective actions promoted by the members of the Proyecto Hermosura in the territory of Cura Malal, province of Buenos Aires, Argentina, and, in turn, from the visual and archaeological work of one of its members and inhabitants of the place, Mercedes Resch, it is possible to read two important movements in this article. On the one hand, the processes of modernization and historical transformation in the community and in the rural-mountain landscape of Cura Malal; on the other, the processes of recovery and preservation of a sense of

$1 *$ Instituto de Investigaciones en Historia y Ciencias Sociales, Universidad Nacional de La Plata.

Tekoporá ${ }^{\circledR}$. Centro Universitario de la Región Este. Universidad de la República (C) Rasic. (2021)

Este es un artículo de Acceso Abierto distribuido bajo licencia Creative Commons (CC BY NC 4.0)
} 
community and landscape that these historical transformations have left as ruins but that, at the same time, emerge as latent forces when we focu critical lense on them. Art and poetry are, in this way, individual and collective actions capable of making that survival visible, as well as protecting the community of Cura Malal and its natural environment from disappearing.

Keywords: art and poetry, Cura Malal, Mercedes Resch, landscape, Proyecto Hermosura

\section{Resumo}

Das ações artísticas, poéticas, arquivísticas e, fundamentalmente, coletivas promovidas pelos integrantes do Proyecto Hermosura no território de Cura Malal, província de Buenos Aires, Argentina, e, por sua vez, do trabalho visual $e$ arqueológico de um de seus membros e habitantes do lugar, Mercedes Resch, será possível ler dois movimentos importantes neste artigo. Por um lado, os processos de modernização e transformação histórica na comunidade e na paisagem rural-montanhosa de Cura Malal. Por outro lado, os processos de recuperação e preservação de um sentido de comunidade e paisagem que essas transformações históricas deixaram como ruínas, mas que, ao mesmo tempo, emergem como forças latentes quando colocamos nosso interesse crítico sobre elas. Arte e poesia serão, desta forma, ações individuais e coletivas capazes de tornar visíveis e sonoras aquelas sobrevivências, bem como proteger a comunidade de Cura Malal e seu ambiente natural do desaparecimento.

Palavras-chave: arte e poesia, Cura Malal, Mercedes Resch, paisagem, Proyecto Hermosura

\section{Introducción}

"La seguridad es el principio de la ruina"

En el año 1880 comienza en la historia argentina un período de profundas transformaciones que constituyeron los cimientos de la Argentina moderna, tanto por los vínculos estrechos que se establecieron con el mercado internacional, colocando los productos del campo en los mercados europeos, como por el creciente control político de unos pocos sobre la mayoría de los ciudadanos y por la expansiva transformación social que implicó la llegada de miles de personas

\footnotetext{
${ }^{2}$ Dicha frase se encuentra grabada en una de las mesas de la pulpería y espacio de arte "La Tranca", ubicado en Cura Malal, Partido de Coronel Suárez, Provincia de Buenos Aires, entre otras frases que los visitantes y habitantes de la región han ido por allí diciendo y dejando. Este punto del mapa de la provincia de Buenos Aires, Argentina, será recorrido durante el desarrollo del artículo.
} 
provenientes de países europeos. Dichos aspectos fueron significativamente acompañados por la incorporación de nuevos materiales, recursos y artefactos tecnológicos que, como el acero, el hierro y el tren, por ejemplo, colaboraron en el crecimiento económico dentro de los nuevos mercados y en la nueva planificación territorial y demográfica del mapa argentino.

Este profundo proceso de transformación colocó a la Argentina entre una de las naciones más modernas de Latinoamérica y sentó las bases de una identidad cultural que hará uso de las incipientes instituciones, como la escuela pública, para su configuración y consolidación del pretendido carácter homogéneo y nacional (Lobato 2000). Pero, como nos sugiere el epígrafe utilizado en este apartado, "la seguridad es el principio de la ruina”, mientras el país sentaba sólidos cimientos económicos, políticos y culturales, este último acompañado de un importante delineamiento discursivo a cargo de los intelectuales de la época para propiciar los pilares de un nuevo sujeto nacional, al mismo tiempo comenzaba un cruento proceso de exterminio sistemático de poblaciones autóctonas y un intento programático del borramiento de sus huellas en el porvenir. Esto fue así ya que, para lograr dicho crecimiento económico, sustentado principalmente en la explotación de la tierra y del ganado, había que incorporar más superficies y ampliar las fronteras de los grandes centros políticos y comerciales, tales como Buenos Aires, desplazando o aniquilando las formas de vida preexistentes en los territorios conquistados.

Si bien el método de apropiación territorial ya había comenzado en Latinoamérica muchos siglos antes con los avances colonialistas e imperialistas de Europa, en el interior del incipiente Estado argentino de finales de siglo XIX se implementaron, con la ayuda de las fuerzas militares y el uso de la población gaucha para ir al frente de la pelea con los nativos, las denominadas "Campañas al desierto", las cuales no sólo anularon bajo el nombre de "desierto" la existencia de habitantes y organizaciones culturales en las zonas a conquistar, sino que también diagramaron las nuevas líneas y límites territoriales del moderno mapa nacional argentino (Ver Fig. 1). De este modo, los intelectuales, políticos y militares a cargo de la formación del Estado Nacional, a fin de justificar esta empresa capitalista, construyeron un fuerte concepto de "desierto poblacional" en el amplio territorio que actualmente comprende el centro y sur de la provincia de Buenos Aires, más todas las provincias argentinas que desde allí continúan hasta la zona más austral del país e inclusive, hasta el Chaco argentino, que les permitió acabar de esta manera con lo que el liberalismo consideraba como "pueblos bárbaros e incivilizados" y ocultar, a la vez, durante más de un siglo, las huellas culturales de las comunidades originarias que habitaron eso que los embanderados del progreso bautizaron como "desierto patagónico" (Lenton, Delrio, Pérez, Papazian, Nagy y Musante, 2015). 


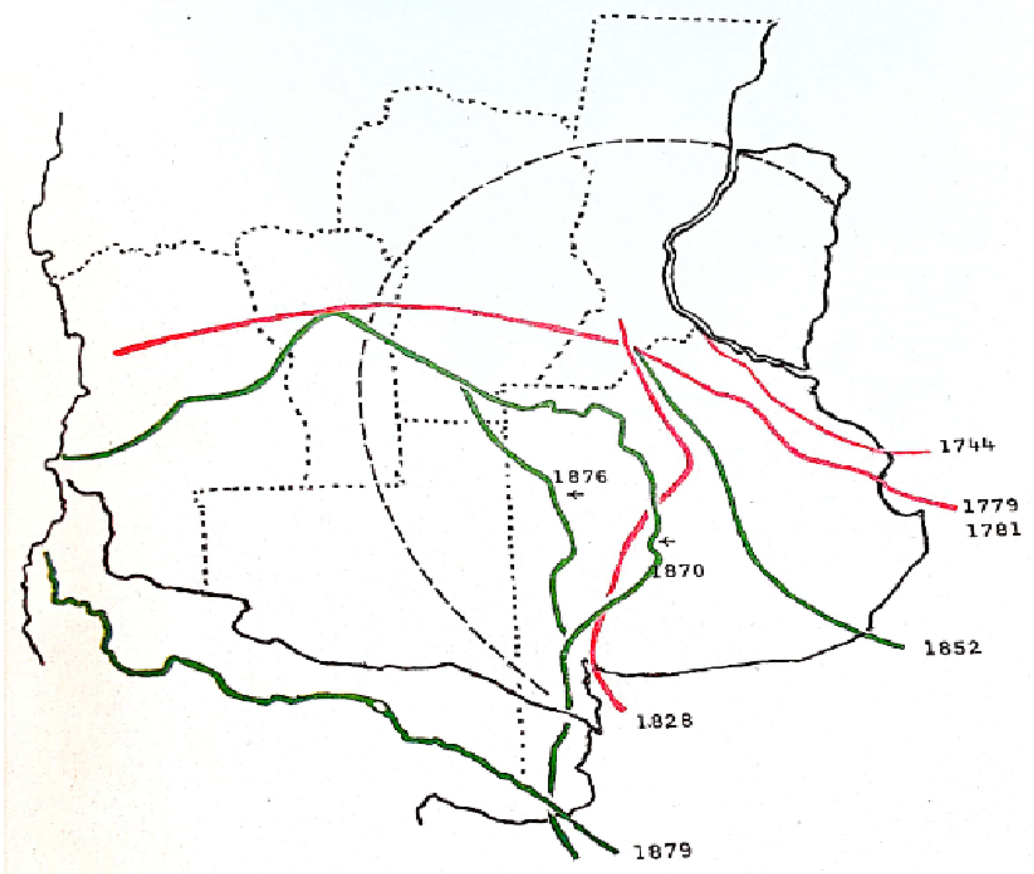

1. Mapa $n^{n} 1$.
Movimientos de la
Jinea de fronteras.
Fisentes J. Wather. La

Figura 1. Mapa del diseño de las líneas de fronteras y conquistas territoriales desde el período colonial (línea roja) hasta el comienzo de modernización nacional (línea verde). Región pampeana de la República Argentina (línea discontinua negra) con fuerte explotación agropecuaria y forestal luego de la expropiación de tierras a los pueblos originarios durante la llamada conquista del desierto (Fuente: J. C. Walther en Fernández López, 1974).

Mientras tanto, con el afianzamiento de estas políticas económicas y culturales fueron el paisaje y los ecosistemas naturales los que también se vieron intervenidos y transformados. Aunque los modos de pensar y de hacer ver las relaciones entre paisaje, política y estética, nos dice Jens Andermann, no hayan acompañado en América Latina, cuna del color y del derroche para los ojos imperialistas, dicho proceso de transformación. Tampoco los modos de cartografiar esos paisajes e historiarlos:

El paisaje, sugiero, es uno de los nodos principales a través de los cuales 
podemos pensar la intersección entre prácticas políticas y estéticas de la modernidad, prácticas del Estado, así como de su contestación por parte de disidencias de cuño "revolucionario" o "conservador". Si en el siglo XIX el paisaje pintoresco del naturalismo romántico fue sentando las bases iconográficas de los emergentes estados oligárquico-liberales, exportadores de materias primas, las transformaciones que fue sufriendo la forma paisaje a lo largo del siglo XX son a un mismo tiempo el índice de la crisis de este sistema político, económico y cultural y del fracaso persistente de trascender sus contradicciones fundamentales. Aún hay una historia por escribir del paisaje moderno, particularmente ahí donde la tierra ha sido y en muchos casos sigue siendo el principal objeto de contienda. ¿Cómo historiar - me pregunto-, en la América latina del siglo XX, los paisajes para el desarrollo, para la revolución, o para el ajuste? ¿Cuáles fueron, o aún siguen siendo, las prácticas políticas y estéticas del espacio, de poder y de resistencia, que conlleva cada uno de ellos? (Andermann, 2008, p.2)

En las zonas rurales de la provincia de Buenos Aires, la división de los campos con el alambrado, el tendido de cables para la energía eléctrica, la interrupción de los rieles y las vías del ferrocarril, el flujo migratorio de las poblaciones, las nuevas técnicas de cultivo y explotación de las tierras, la multiplicación del ganado, las nuevas edificaciones, etc., serán, entre otros tantos más que vendrán durante el desarrollo del siglo XX y actual XXI, los elementos de una modernización que, si bien fueron funcionales, como ya se ha dicho, a la sólida construcción de las bases políticas y económicas de un Estado Nación, produjeron una importante fragilidad en los ecosistemas regionales: la afectación climática, la migración y hasta exterminio de especies autóctonas o saturación de la tierra por el monocultivo pueden hoy en día a la distancia ser uno de los ejemplos más sustanciales. Pero al mismo tiempo, siguiendo a Andermann, produjeron una relación con los paisajes naturales cosificada o mediada, en un primer plano, por una mirada iconográfica y extractivista. De este modo, lo que también entra en crisis durante estos procesos de transformación, y esto será de particular interés en este trabajo, son las formas de percepción del paisaje por parte de los sujetos que lo habitan y los lazos comunitarios construidos entre esos sujetos y su entorno natural no humano (Rivera Cusicanqui, 2015). Estos dos aspectos invisibilizados a lo largo de la historia constituyen aquello que Bernardo Canal-Feijóo, un poeta e intelectual argentino, llamó en 1932 "despaisimiento ${ }^{3}$, una expresión que, a diferencia de la noción de "desierto" aplicada por la campaña capitalista y progresista de los comienzos del siglo XX, permitió poner en evidencia una política sustentada en el deshacimiento del paisaje natural y cultural, es decir, en la descomposición y borramiento programático tanto de los rasgos y elementos naturales de las regiones, como de los rasgos culturales y las formas de vida comunitaria que junto con el paisaje se configuran y ensamblan. Los jornaleros de

\footnotetext{
${ }^{3}$ Durante el período de conquista militar, el Noroeste argentino, territorio desde donde Canal-Feijóo escribe, comenzó a ser fuertemente deforestado para la construcción, por ejemplo, de los durmientes del ferrocarril y para las instalaciones portuarias de Buenos Aires. A su vez, el posterior reemplazo de la madera del quebracho por otra con orígenes fuera de la región produjo otro fuerte "despaisamiento" cultural: la concentración de población trabajadora que la empresa forestal allí había montado se vio obligada a desintegrarse (Viñuales, 2010).
} 
Santiago del Estero, provincia del noreste argentino, escribe Canal-Feijóo, "se encontraron más pobres que al nacer, pues hasta habían perdido su paisaje". El habitante de esa región, continúa Canal-Feijóo, "un día se halló súbitamente solo y desguarnecido. Con la última jornada se había ido su paisaje, y el abra de aquel día era ya su destierro. Fue como un súbito despaisamiento" (1934, p. 61-62).

Cabe destacar que los pueblos originarios de la región ya contaban con un modo de organización económica y territorial de la tierra. Me refiero a los llamados "corrales de piedra" hechos a base de pirca y destinados a la guarda de ganado mayor y menor, a lugares para la captura y/o manejo de caballos y vacas cimarrones, a espacios de vivienda donde se habrían realizado actividades domésticas, a emplazamientos fortificados y puntos de avistaje y vigilancia del territorio (Pedrotta, 2011). No obstante, estos, los corrales de piedra, constituyeron una forma mucho más orgánica y comunitaria de distribución, de circulación, de hábitat y de convivencia entre agentes humanos y no humanos que las formas que la modernidad capitalista impuso con sangre en el territorio y en el paisaje, tales como el alambrado. Incluso en la zona de Buenos Aires que puntualmente este artículo focaliza, Cura Malal, las sierras que forman parte del paisaje constituyeron también una forma natural de esos corrales de piedra (Ver Fig. 2).

Será justamente desde el sentido de paisaje como "ensamble" que va del entorno a la imagen y viceversa (Andermann, 2008), el que me permitirá recuperar aquello que el proceso modernizador ha intentado poner "en ruinas", o bien exterminándolo, o bien reduciéndolo a una mera construcción de la mirada que lo abarca y al resultado material que la intervención humana deja al "culturizar" el entorno natural. Trabajar con las ruinas, es decir, con los restos de lo que alguna vez fue, nos pone a buscar - o al menos es la responsabilidad crítica a la que esas ruinas nos enfrentan-los modos de visibilizar y hacer sonar esas supervivencias ensambladas con el paisaje. De esta forma, me pondré a explorar esos restos en las relaciones entre el arte, la comunidad y el paisaje de un pequeño punto del mapa de Buenos Aires: Cura Malal. Las acciones artísticas y poéticas coordinadas por el Proyecto Hermosura y la particular obra visual de una de sus integrantes, Mercedes Resch, ambas realizadas en dicho territorio, darán cuenta de un sentido de comunidad y de ensamble con el paisaje latente, así como también de otros modos de cartografiarlo, visibilizarlo y preservarlo de su desaparición. 


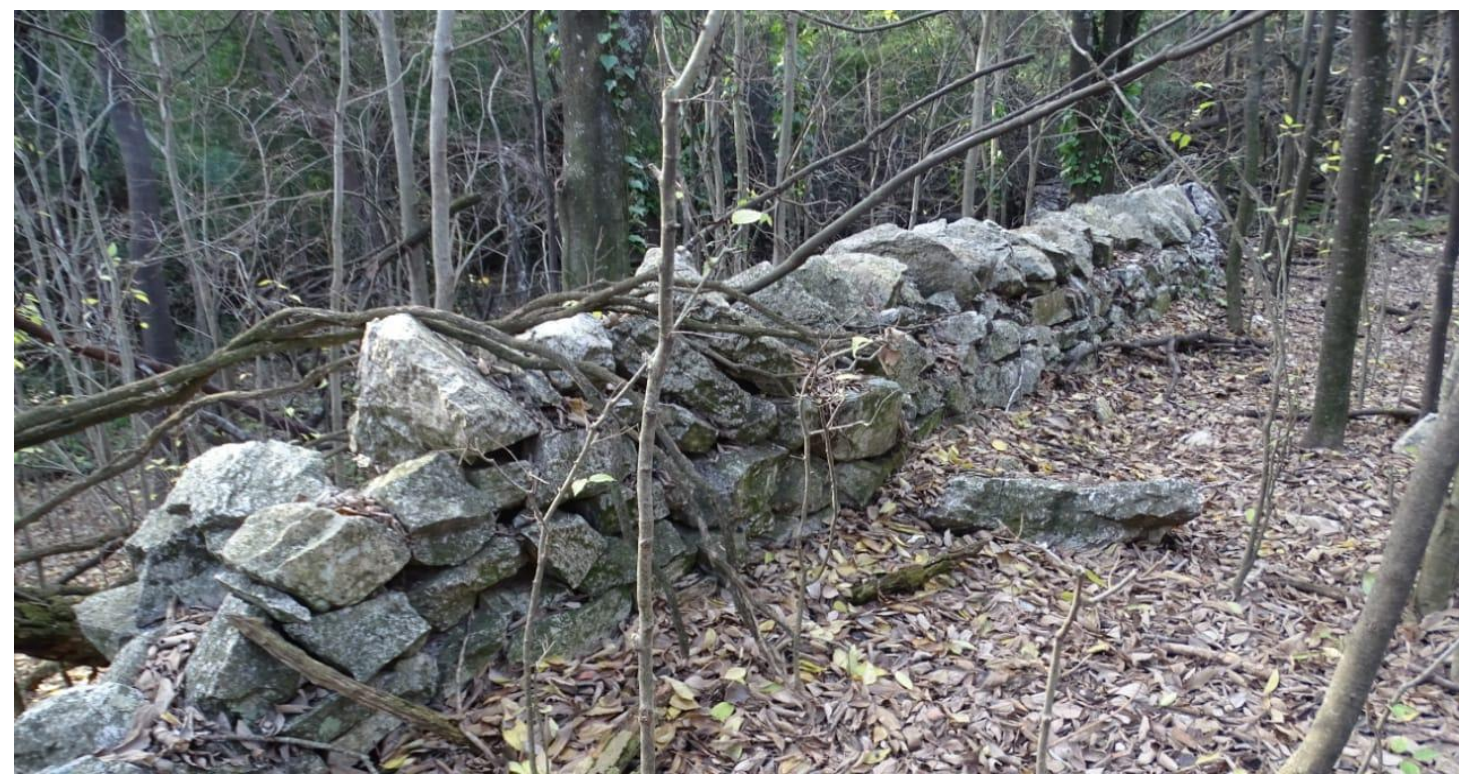

Figura 2. Restos de un corral de piedra semicircular situado en un campo privado de Cura Malal, Partido de Coronel Suárez, provincia de Buenos Aires. El cordón serrano que forma parte de ese territorio completa la pared circular del corral (Fotografía tomada en el año 2020. Gentileza de Mercedes Resch).

\section{El corral de piedras}

En el partido de Coronel Suárez, provincia de Buenos Aires, a 15 kilómetros de la ciudad cabecera y a $3 \mathrm{~km}$ de la ruta provincial 67, se encuentra Cura Malal, un territorio que en plena llanura pampeana convive con un sistema de cordón serrano capaz de alcanzar, en su máxima expresión, los 1200 metros de altura (Figura 3). Desde allí, desde lo alto, las sierras también han sido testigos de numerosos enfrentamientos armados durante las ya mencionadas "campañas al desierto" de la historia argentina.

Al finalizarse dichas empresas militares, las tierras de esta porción de la provincia de Buenos Aires fueron entregadas, como formas de pago, a jefes, oficiales y soldados que hasta entonces habían participado en el triunfo de estas tierras, producto de su sangriento quite a los habitantes originarios. De esta manera, en 1878, el territorio donde se encuentra ubicado hoy en día Cura Malal fue otorgado en concesión para su explotación al coronel Ángel Plaza Montero. El convenio para dicha explotación dejaba constancia de que el concesionario debía fundar un establecimiento ganadero para el perfeccionamiento y cruza en gran escala del ganado para su exportación a Europa, introducir en el mismo plazo padrillos de pura sangre, para fomentar la cría de caballos de silla y, por último, facilitar todos los medios para radicar en el lugar 60 familias europeas, con el fin de que se dedicaran a las actividades agrícolo-ganaderas. No obstante, la crisis económica que advino hacia finales del siglo XIX hizo que estas tierras sean vendidas a una sociedad anónima, cuyo presidente hoy le da nombre a uno de los partidos de la zona, Ernesto Tornquist, para comenzar luego de la crisis un remate extensivo de fracciones territoriales (Dos Santos, 2004). Estos mecanismos de 
apropiaciones, entregas y concesiones constituyeron las bases del proceso de modernización en la zona. También de lo que hemos denominado, por medio de Canal-Feijóo, como "despaisamiento".

La fecha de fundación de Cura Malal como pueblo se fija el 17 de septiembre de 1905 cuando se llevó a cabo una subasta de lotes, basada en el plano que fuera medido y trazado por el ingeniero Nicolás Valsoe: 48 manzanas repartidas en una superficie de 90 hectáreas en venta "completamente liberal y sin base" (Rodríguez, 1908). Desde entonces, el grueso de la población estuvo ligada al trabajo rural de las Estancias que allí quedaron conformadas, "La Curamalán" y "La Cascada".

Como tantas otras, la localidad tiene distinto nombre que la estación de trenes, aunque en este caso parece sólo un error de apreciación. Cuando llegó el ferrocarril, en 1884, como parte del proyecto modernizador, bautizaron al lugar con el nombre de Curumalán y luego se le puso el nombre del cerro ubicado a 35 kilómetros, cuya estación ferroviaria homologó, llamado Cura Malal, que en la lengua de los indios pampas quiere decir "corral de piedras". A su vez, este nombre, y por lo ya referido en el apartado anterior, también hace alusión a la función que dichos pueblos adjudicaron a las piedras y elevaciones naturales del lugar. ${ }^{4} \mathrm{Si}$ bien el "emisario del progreso", como llamó en el siglo XIX el intelectual argentino Domingo Faustino Sarmiento al tren, se detuvo hasta el año 2016 en Cura Malal cuando los pasajeros y las pasajeras anunciaban su presencia con señales de linterna, en la actualidad, ha dejado de hacerlo en casi todos los pueblos de la provincia de Buenos Aires, excepto las estaciones de ciudades cabeceras (Rasic et al., 2019). Esta desactivación del funcionamiento ferroviario, producto de históricas decisiones políticas y económicas, produjo en dichos pueblos un gran aislamiento territorial y un importante vaciamiento poblacional, a la vez que un olvido cada vez más progresivo ante la miopía de los grandes centros urbanos (AA.VV, 2010). Si bien Cura Malal llegó a tener más de mil habitantes, el censo del año 2010 dio como resultado 94, una porción muy pequeña de personas frente al millar de pobladores que vivían en la localidad en la primera década del siglo XX, antes de la mecanización de las tareas agrícolas, la desactivación ferroviaria y la construcción de rutas pavimentadas (Dos Santos, 2004). La insistente modernización extendida en el espacio y en el tiempo, de este modo, fue construyendo otro "desierto".

No obstante, resistiendo a la historia y al olvido, en este corral de piedras, firme testigo del correr del tiempo, del viento y de las nubes, la vida, el arte y la comunidad laten con fuerza. Desde el año 2007 se viene desarrollando en el lugar un proyecto poético documental de intervención territorial, Proyecto Hermosura, que recupera por medio del arte colectivo la memoria de un pasado atravesado tanto por el paso y el murmullo del tren, como por el silencio de los pastizales y

\footnotetext{
${ }^{4}$ Según el testimonio de los pobladores y las pobladoras más antiguas del pueblo, el nombre "Curumalán" circuló hasta pasada, inclusive, la mitad del siglo XX. En diarios antiguos de la zona podemos encontrar escrita también la misma palabra. De una u otra forma, la variedad y alternancia de dichos nombres hablan, al menos, de dos aspectos significativos: los restos de la lengua araucana y su paisaje en el oído de los habitantes y los intentos de su transcripción escrita por parte del proceso de modernización.
} 
por un horizonte visual sin fronteras: un ensamble temporal y paisajístico que allí persiste a modo de archivo vivo.

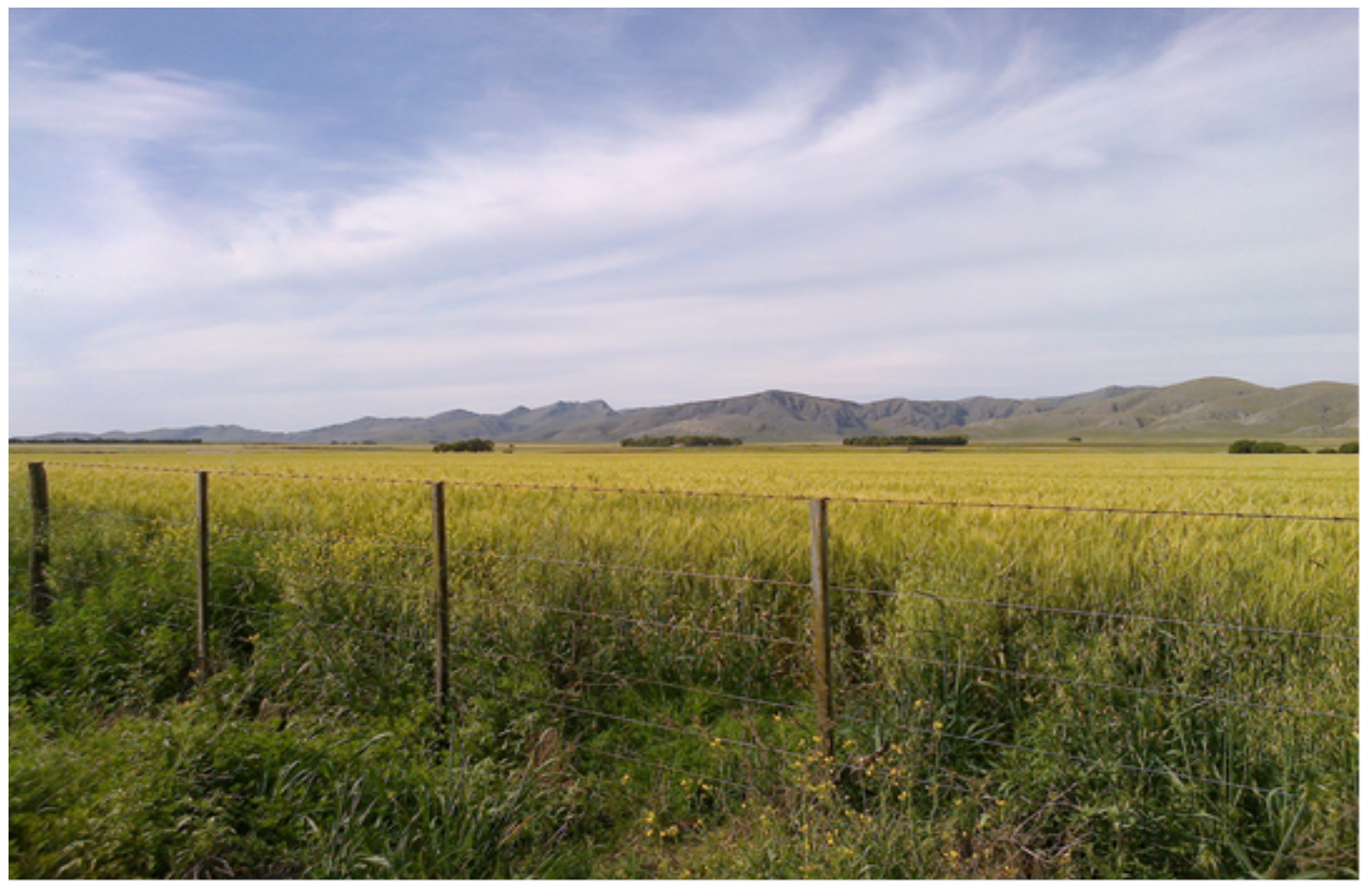

Figura 3. Paisaje rural y serrano de Coronel Suárez, provincia de Buenos Aires (Fotografía tomada en el año 2015. Gentileza de Mercedes Resch).

\section{De la campana al tren que pasa}

Proyecto Hermosura es, como su nombre lo indica, un proyecto desarrollado por Verónica Suanno, Nilda Rosemberg y Mercedes Resch; tres mujeres, artistas y docentes que trabajan juntas desde finales de 2007 con foco en la territorialidad de Cura Malal. Desde su inicio, este proyecto se propuso generar una reflexión a partir del encuentro con la realidad de algunas comunidades rurales del sudoeste de la provincia de Buenos Aires. El proyecto ha gestionado y llevado a cabo desde sus comienzos numerosas actividades ${ }^{5}$

5 Entre las actividades referidas se encuentran: investigaciones poético-documentales en permanente proceso, tales como las llevadas a cabo en las entrevistas realizadas a los habitantes de Cura Malal y el relevamiento de sus archivos personales; realización de encuentros colectivos, tales como peñas y fogones, mapeos comunitarios, ollas populares y la realización del mural comunitario en Cura Malal; exposiciones en diversos lugares de la provincia de Buenos Aires: espacio de arte "La Tranca" de Cura Malal; "Espacio de Arte Isidoro" y Museo del Mercado de Coronel Suárez; espacios públicos de Sierra de la Ventana; "Facr C", espacio de arte de la ciudad de Bahía Blanca; Biblioteca Campano de Tres Arroyos; y en "Elgón”“Barraca Vorticista” y "Arte BA” de la ciudad de Buenos Aires; centro cultural "El hormiguero" de la ciudad de La Plata; Teatro Auditorium, Centro Provincial de las artes, de la ciudad de Mar del Plata; taller de dibujo al aire libre en Villa Arcadia, provincia de Buenos Aires, y taller tejido comunitario en la $1^{\text {a }}$ Feria del Libro en Sierra de la Ventana, provincia de Buenos Aires, y en la Feria de Editoriales Autoconvocadas, Casa de la Cultura de la UNS, Bahía 
En el año 2009, otro proyecto abraza la causa y amplía la plataforma de trabajo. Nace así Corral de Piedra, de la mano de Mercedes Resch y Fernando García Delgado. Este es un proyecto artístico-cultural, abierto y participativo, el cual cuenta a la vez con el Taller de Arte y Producción donde se desarrollan actividades plásticas para niñas y niños, clases de danzas folklóricas, malambo, tango y canto. Desde entonces vienen recuperando la historia del pueblo y de la región, documentos escritos, audiovisuales y orales, para lo cual se está construyendo un espacio físico para el archivo y la biblioteca.

Durante la primera etapa de trabajo, sus integrantes propulsaron encuentros con los habitantes del pueblo. Estos consistieron en una serie de visitas, de aproximaciones al universo de estas personas situadas en su contexto. Los registros audiovisuales sirvieron de documentos-escucha y memoria del encuentro, relatos - para ser luego traducidos a un lenguaje poético. La utilización de recursos visuales, escritos, sonoros, espaciales son las herramientas que desde entonces utilizaron para crear y poner en valor una suerte de archivo vivo. Archivo resultante de la experiencia de unir lo documental con lo poético, entendiendo como fundamental la importancia del paisaje como producto de la cultura de las y los habitantes y como causante de las especificidades que conforman la hermosura del lugar. A partir, entonces, de la gestación de una segunda etapa de encuentros colectivos que propiciaron el hacer con el otro en un tiempo compartido (caminatas por el lugar, peñas musicales, ollas populares o meriendas en el invierno) se han realizado distintas actividades comunitarias, tales como la intervención de paredes con artistas invitadas, instalación de obras visuales con artistas residentes en el lugar, mapeos visuales y sonoros realizados con los habitantes del pueblo (Rasic et al., 2019). Estos últimos fueron realizados a partir del dibujo de cartografías personales que dan cuenta de los trayectos y desvíos cotidianos, es decir, la relación de los sujetos con el territorio que transitan y la percepción del mismo. También a partir de registros sonoros del paisaje en una pieza de audio realizada por el músico invitado Javier Ortiz, la posterior puesta en común con las y los vecinos y la identificación de los sonidos naturales, de las voces

Blanca, también provincia de Buenos Aires; permanentes intercambios con artistas, tales como los músicos Tata Cedrón, Juián Pessi e Irupé Tarragó Ros; el artista plástico Fernando García Delgado y otros que formaron parte de "Originario", un proyecto de residencia de mujeres de la provincia de Buenos Aires y alrededores; publicaciones abiertas, artesanales y autogestivas como las iniciadas en el año 2008 con el apoyo del Instituto Cultural y la Municipalidad de Coronel Suárez, "Proyecto Hermosura”, y una publicación en el año 2019 en una revista de divulgación científica internacional, El taco en la brea, Año 6, N 10; una participación en el X Congreso Internacional de Teoría y Crítica Literaria.Orbis Tertius 2019 (IdIHCS, UNLP/-CONICT), ciudad de La Plata, provincia de Buenos Aires y en las III Jornadas HU-uhma, Casa de la Cultura, UNS (2009), ciudad de Bahía Blanca, provincia de Buenos Aires y residencias de artistas, investigadoras/es y de viajeras/os en el hospedaje rural que propician llamado "El Gallinero". Desde el 2010, se desarrollan actividades en "La Tranca", una pulpería y espacio de arte autogestionado por Mercedes Resch en donde antiguamente funcionaba un boliche típico de pueblo llamado "lo de Leonhardt" y que hoy en día también funciona como espacio de talleres, muestra de arte, charlas y propone hospedar, en un anexo edilicio llamado "El gallinero", a artistas y viajeras/os que deseen experimentar la vida en ese entorno o en un formato de residencia. Ver: http://corraldepiedra.com.ar/la tranca/index.htm 
y de los espacios donde habían sido registrados. Veamos a continuación algunos de estos mapeos colectivos:
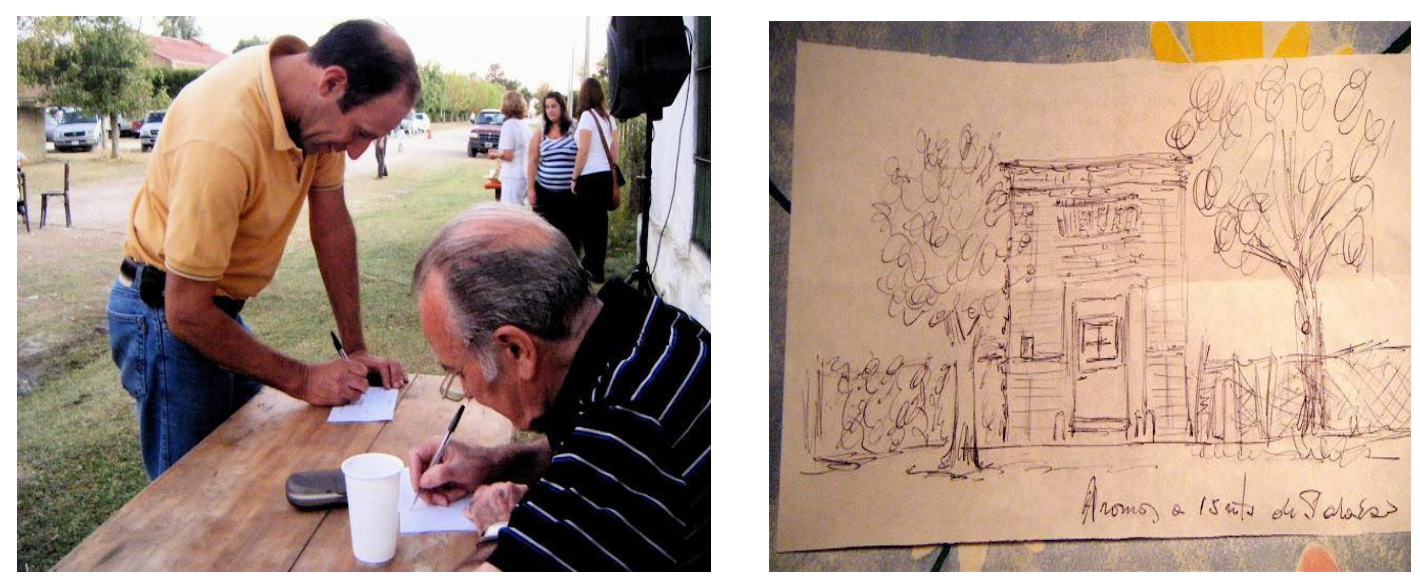

Figura 4. Participación de las vecinas y los vecinos de Cura Malal llenando las fichas durante la jornada de presentación del proyecto en el territorio (Año 2007).
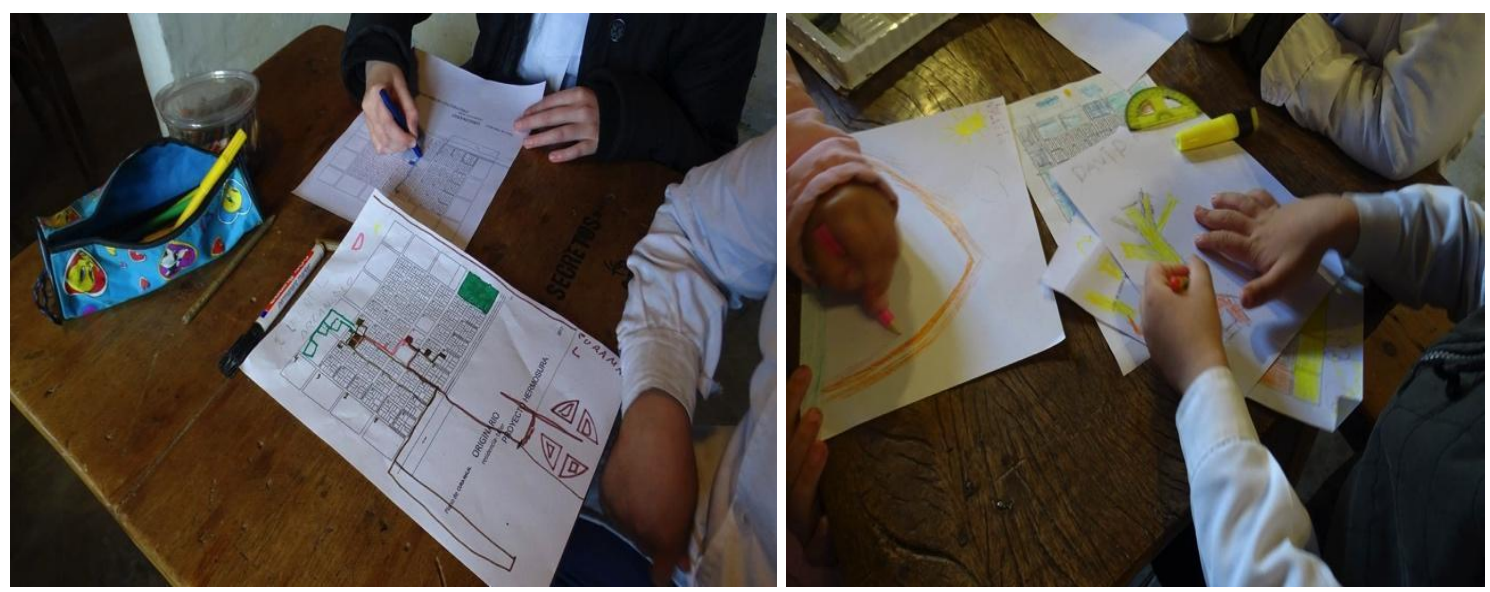

Figura 5. Intervención de planos del pueblo realizados durante la visita a la muestra por las alumnas y los alumnos de la Escuela Primaria $N^{\circ} 6$ de Cura Malal (2018). 

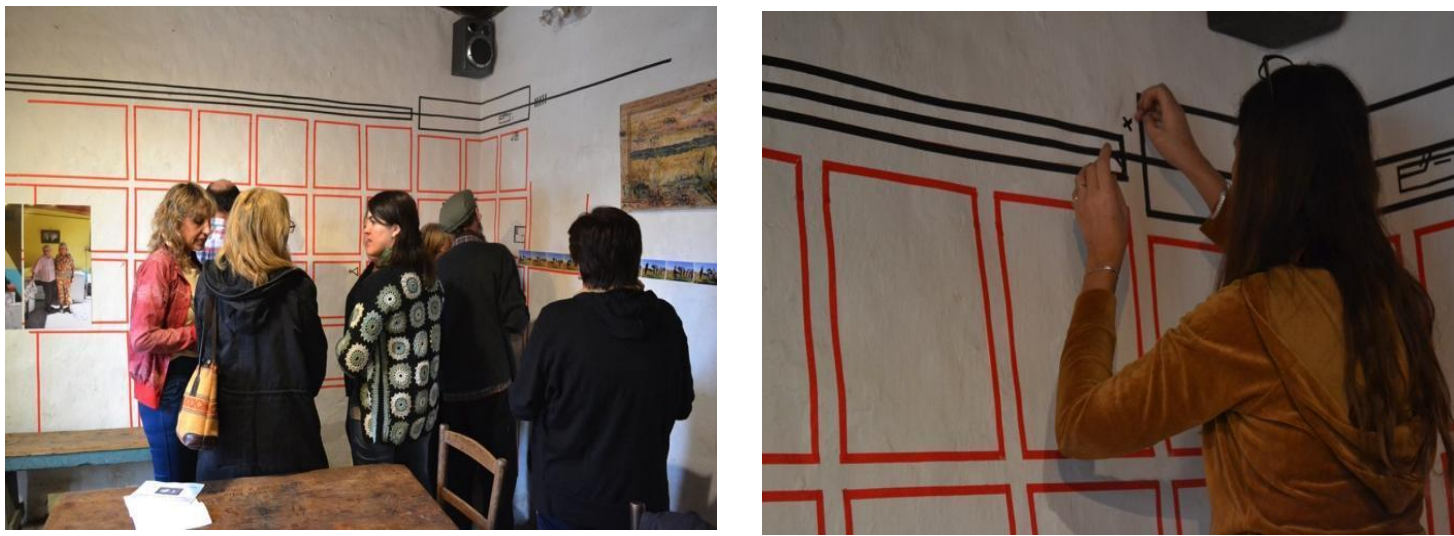

Figura 6. Originario, muestra de la Residencia coordinada por Proyecto Hermosura, en "La Tranca”, Cura Malal (2018).

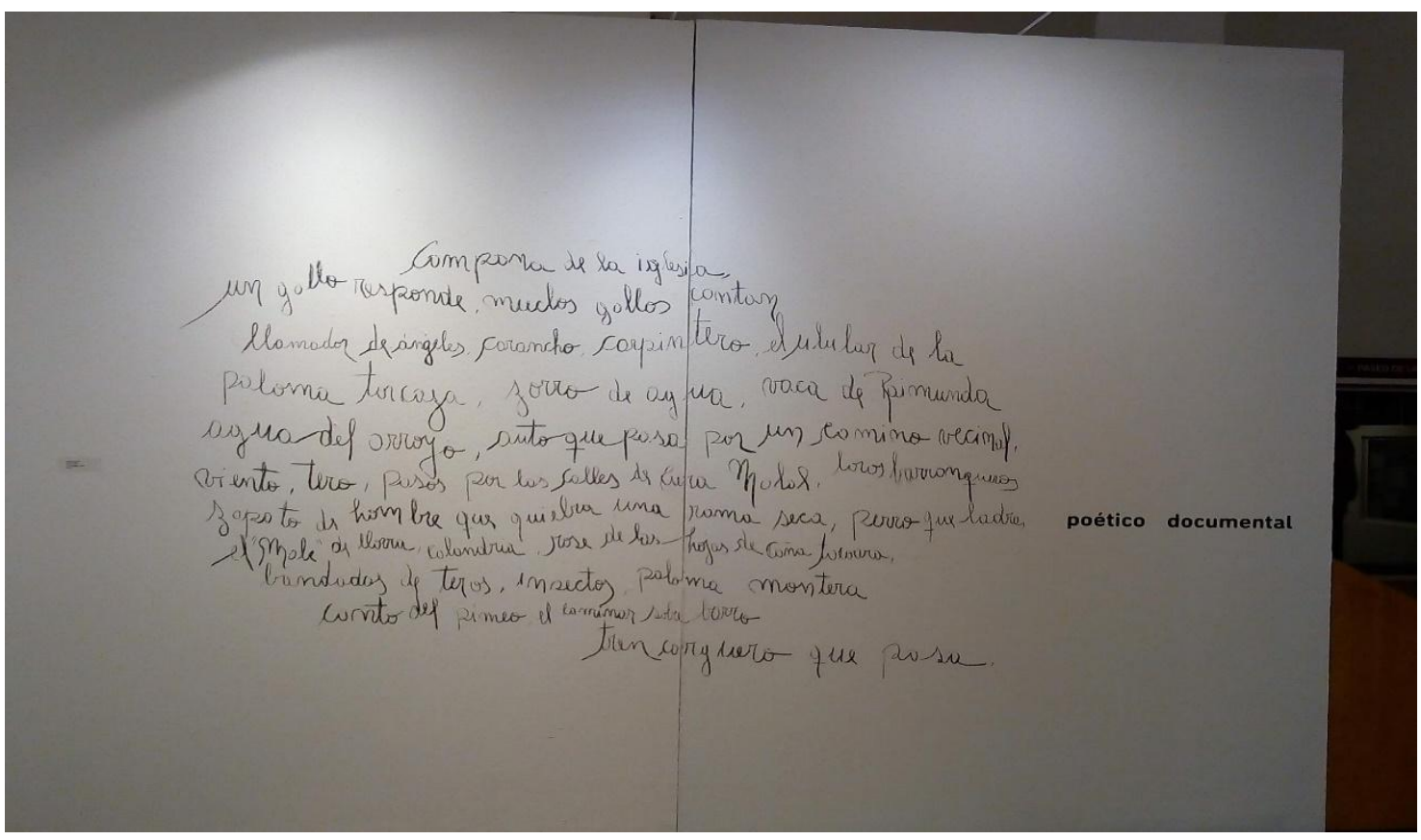

Figura 7. Poema visual escrito con grafito que acompaña el paisaje sonoro que se escucha en auriculares (2018).

Estas imágenes, provistas todas por las coordinadoras del proyecto y disponibles en el espacio virtual de libre acceso, ${ }^{6}$ registran el trabajo realizado con la gente del lugar y con artistas residentes sobre una misma consigna que los reúne y funciona como soporte: el territorio de Cura Malal atravesado por distintas miradas, experiencias y recorridos. Estas divergencias construyen una cartografía que se aparta de las líneas rectas y tensas configuradas por el diagrama modernizador del pueblo, del cual el tendido de los cables de luz, del alambrado y de las vías del tren acompañan en dicho diseño rectilíneo, para acercarse a dibujos y caminos más orgánicos: "los del ganado cuando va a pastorear, los del árbol que se cae por la tormenta, los de la huerta que se ensancha y rompe con los canteros

\footnotetext{
${ }^{6}$ Ver el blog http://proyectohermosura.blogspot.com/
} 
pautados, los caminos de la bicicleta o los escondites detrás del árbol grande" (Resch et al., 2008, s/p). En términos de Gilles Deleuze y Félix Guattari (1976), ampliar el territorio no por acumulación o estratificación sino por desterritorialización, es decir, por otras lógicas capaces de producir líneas de fuga y trazos alternativos al modelo de planificación modernista y hallar, en ese camino, puntos de intensidad dentro del mapa que parecían estar desprovistos de vida y de conectividad entre sí.

Si miramos y escuchamos el poema visual escrito a partir del registro sonoro hecho por el músico invitado Javier Ortiz, encontramos no sólo el reconocimiento preciso de los elementos del territorio y su paisaje por parte de sus habitantes, sino también el ritmo que la relación de dichos elementos con los sujetos componen, y la huella de un silencio que es parte de ese ritmo, pero que a la vez está cargado de otro tiempo y otra dimensión. Hagamos primero, para ello, la transcripción del poema para leerlo más cercanamente:

Campana de la iglesia,

un gallo responde, muchos gallos cantan

llamador de ángeles, carancho, carpintero, el ulular de la

paloma torcaza, zorro de agua, vaca de Raimunda

agua del arroyo, auto que pasa por un camino vecinal,

viento, tero, pasos por las calles de Cura Malal, loros

barranqueros

zapato de hombre que quiebra una rama seca, perro que ladra

el Male que llora, calandria, roce de las hojas de caña tacuara,

bandadas de teros, insectos, paloma montera,

canto del pimeo, el caminar sola, barro

tren carguero que pasa.

En una primera lectura, vemos aparecer en el poema los elementos que forman parte del paisaje de Cura Malal: animales, aves, vegetación, insectos, una mujer, un hombre, un auto y un tren que pasa. Todos estos son identificados por sus habitantes con un grado de conocimiento y proximidad tal que con el tan solo acto de la escucha pueden clasificarlos con nombres y ubicaciones específicas: una paloma torcaza, un zorro de agua, la vaca de Raimunda, un camino vecinal, etc.

A medida que estos van apareciendo en el poema y en la escucha imaginaria, puesto que aquí no contamos con el registro del audio (aunque esa falta nos permite jugar con otros sentidos), van componiendo un ritmo peculiar, marcado tanto por las comas y los versos que la copista, Mercedes Resch, ha colocado y configurado, como por el paisaje también imaginario que vamos evocando a medida que leemos. Este nos propone un ritmo que se mueve en segmentos breves e irregulares y más de una vez interrumpidos por los quejidos y roces de ciertos sonidos que logran escucharse en los fonemas más fuertes, tales como "perro que ladra" u "hombre que quiebra una rama seca", y que nos permiten detectar el paisaje tanto en la voz de quienes lo habitan, como en su puesta en voz de la escritura (Milone, 2017). A la vez, la enumeración de imágenes sensoriales que conviven simultáneamente, es decir: todas al mismo tiempo, en el poema (procedimiento que lo aproxima, incluso, a los rasgos y ritmo de un poema vanguardista en plena llanura pampeana), logra ser interrumpida por la pausa 
prolongada entre los dos últimos versos y por el paso final del tren de carga que da cierre a la escucha y al texto. Es justamente en esta pausa marcada por el espacio en blanco en la hoja donde se instala, por un lado, un horizonte, un límite territorial preciso: las vías del ferrocarril que separan al pueblo de otras comunidades aledañas y lo cerca en una imposibilidad de ir más allá sobre rieles, puesto que ese tren ya no conecta estaciones y distribuye gente, sino que tan sólo carga y se constituye, de este modo, como un elemento estático más del paisaje visual y sonoro de Cura Malal. Por otro lado, esa pausa espacial en el texto sugiere la presencia de un silencio significativo con el que, sin embargo, es posible escuchar con su lectura, las resonancias de una temporalidad más lenta capaz de dar cuenta de un procedimiento diferente: el ensamble de distintos elementos, dimensiones y tiempos en un mismo espacio (el del poema) y en un mismo territorio (Cura Malal). Puesto que, lo que vemos y escuchamos aparecer con la pausa en el texto es la bisagra no sólo entre el pueblo de Cura Malal y otras comunidades aledañas como ya se ha señalado, sino también entre la naturaleza, su flora y su fauna, y el dispositivo tal vez más representativo del proceso de modernización nacional que, como también ya se ha señalado en la introducción, ha producido justamente con su avance progresivo y civilizatorio el borramiento de estas coexistencias: las del canto de una paloma torcaza en un presente activo y cercano con el sonido de un tren que más de un siglo después de su fundación carga, más que con arena, piedra y cereal, con el peso de las múltiples temporalidades, sobre todo las de un porvenir incierto, y el del silenciamiento de ellas a lo largo de su recorrido por la historia. Afortunadamente, el poema y el arte colectivo impulsado por Proyecto Hermosura las pone en evidencia y documenta como parte de su arte dichas experiencias para que no las enterremos en el olvido. En simultáneo, dentro de ese gran archivo vivo que el corral de piedras resguarda, la obra visual de la artista Mercedes Resch, una de las integrantes del Proyecto y habitante de Cura Malal, nos permite descubrir que bajo tierra también hay una memoria poética que desenterrar para configurar otra narrativa de la historia y otra cartografía del lugar y su paisaje.

\section{El silencio de los pastizales}

Nuevamente el silencio aparece como sonido privilegiado para escuchar, justamente, lo que se halla a la espera de ser detectado: un resto de historia del paisaje y en el paisaje. Es así como en simultáneo a las acciones poético documentales impulsadas por el Proyecto Hermosura, una de sus coordinadoras, la artista y docente Mercedes Resch, comienza a producir entre el año 2012 y 2013 en Cura Malal (y aún continúa sin cerrar el armado) una pieza de arte llamada "Silencio de los pastizales", la cual, sobre la llanura de una tela blanca, se pone a coser con hilo pedazos de alambres oxidados y de secretos. En el prólogo escrito con lápiz para la edición artesanal de su proceso creativo, el cual se encuentra en el domicilio de la artista, ésta nos dice:

Silencio de los pastizales, testigos mudos del cambio. El hombre con su necesidad de controlar y determinar su territorio, alambra poblando las tierras. Se mide, se estaca, se alambra. Así aparece el alambrado, grueso, duro, delimitando los espacios para el ganado, las tierras sembradas y la propiedad del hombre. Se construye un pueblo. 
El alambre fue la reja por donde se empezó a ver el horizonte.

Alambres oxidándose bajo la tierra, por más de treinta años. Los he desenterrado del jardín del gallinero, cerca del pozo ciego. Los junté por mucho tiempo en baldes y fuentones. Estos alambres me resultan especiales, transformándose todo el tiempo, corroídos; cuentan parte de una historia. Los tomo, les saco la tierra, solo queda el óxido y empiezo a dibujar con ellos sobre una tela blanca. Los miro, los corro, los toco, siento su rugosidad, sus deformaciones, los acerco, los alejo y, finalmente, cuando combino una trama, los coso con hilo negro. De esta manera construyo mi proceso de trabajo creativo. (Resch, 2013, s/p) ${ }^{7}$

Entre el territorio y pasado personal de Resch y el territorio y pasado de la región serrana que integra Cura Malal se inscribe esta obra (aunque también, entre lo subjetivo y lo colectivo, todos los relatos de la historia). La autora desentierra de una cartografía familiar y cotidiana-"el jardín del gallinero, cerca del pozo ciego"-no sólo pedazos de alambres corroídos por la vida bajo tierra (¿también restos del tren que pasaba por allí tal vez?) y por los recuerdos de quien los busca y encuentra, sino además por la acumulación de tiempo y de olvido:

Quien procure aproximarse al propio pasado sepultado, debe comportarse como un hombre que excava. Sobre todo, le está vedado intimidarse ante el retorno, una y otra vez, sobre una y la misma circunstancia-debe esparcirla como se hace con la tierra, removerla como se remueve la tierra. Puesto que las "circunstancias" no son más que estratos, que sólo tras la más cuidadosa indagación arrojan aquello que hace que la excavación valga la pena. (Benjamin, 1992: tomo IV, 400)

Además de una cuidadosa costura y organización de hilos metálicos, la obra de Mercedes Resch es en sí misma, en el sentido que la cita de Walter Benjamin nos señala, un trabajo de excavación arqueológica y, a la vez, un trabajo de colección, exhumación y archivación (Bocchino, 2010; Gerbaudo, 2013; Goldchluck y Pené, 2013) de restos que recupera, principalmente, tanto por la temporalidad, materialidad y tramas de los objetos con los que se trabaja, como por el acto mismo de "desenterrarlos" y de ponerlos a respirar en otra superficie para también darlos a mirar y a resignificar, una memoria orgánica del lugar. Esta, cuando sale a la luz, opera en doble movimiento o "doublé bind" (Derrida, 2013) y desactiva, por ello, su funcionamiento dialéctico, puesto que pone en evidencia tanto el paisaje que fue como el que ya no es, su recuerdo de ausencia y su olvido de presencia a la vez. Pero la obra de Resch no se agota solamente en este efecto de lectura, sino que también logra poner en evidencia con su potencia creativa y arqueológica un sistema de privatización económica que ha transformado para siempre el silencio de los pastizales en ruidosas jaulas cartesianas. Es, inclusive, con este juego de

\footnotetext{
${ }^{7}$ La obra de Mercedes Resch fue expuesta el 27 de julio del 2013 en el espacio de arte Barraca Vorticista, Buenos Aires-Argentina. La autora cuenta también con otras obras en proceso, tales como "ABCdeMe", realizada con alambres, madera, tierra de Cura Malal, piedras, ramas y tinta china. Esta fue expuesta en el 2018, junto con la obra de Leandro Vesco, en el Museo Benito Quinquela Martín, Buenos Aires-Argentina. Resch apuesta nuevamente allí a la obra como cartografía y paisaje.
} 
imágenes sensoriales que las palabras utilizadas para dar nombre a la obra señalan donde también queda a la vista, y hace ruido, que lo que se ha ido transformando silenciosamente "cerca del pozo ciego" son nuestros modos de percibir el cielo, el horizonte, el paso y la contextura del tiempo. La mano y el ojo de Mercedes Resch nos recuerdan, esperanzadoramente, que los alambres y los fierros pueden doblarse, coserse como algodón y lienzo suave y hasta transformarse en poemas, narraciones, caligramas por donde leer, tocar y ver, desde otra lógica, el trazado del vuelo de los pájaros, la continuidad de las nubes, las arrugas de las sierras: un paisaje con relieves y sin alambres. ${ }^{8}$ A la vez, como toda obra con potencia de archivo, imágenes con las que es posible experimentar, a través de todos los sentidos, fragmentos, espacios en blanco y agujeros de memoria por donde se cuelan los pasados aún por venir (Didi-Huberman, 2007; Antelo, 2015).

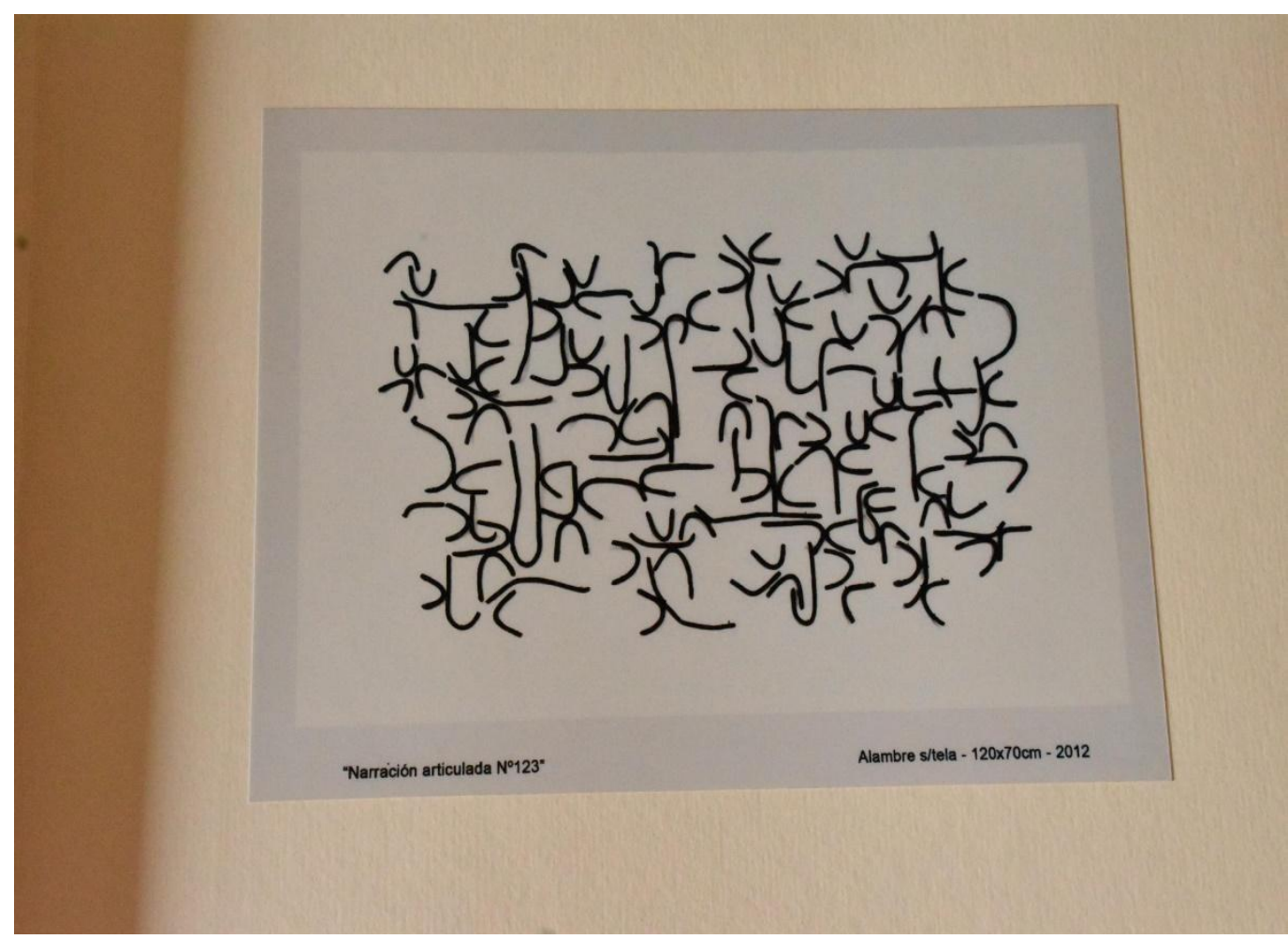

Figura 8. "Narración articulada $\mathrm{N}^{\circ} 123$ ”. Alambre sobre tela- $120 \times 70 \mathrm{~cm}$. Autora de la obra: Mercedes Resch

\footnotetext{
${ }^{8}$ La artista visual Belén Gache lee en estas piezas de Mercedes Resch restos de escrituras asémicas, alfabetos desconocidos y lenguajes olvidados que las reenvían, a su vez, a una amplia tradición artística en Occidente que va del Ars Poetica de Horacio a los alfabetos de Paul Klee, las artes visuales de Kandinsky, las escrituras chinas de Michaux e, inclusive, en un más acá latinoamericano, las obras de Xul Solar y los dibujos de Dermisache (2013, s/p).
} 


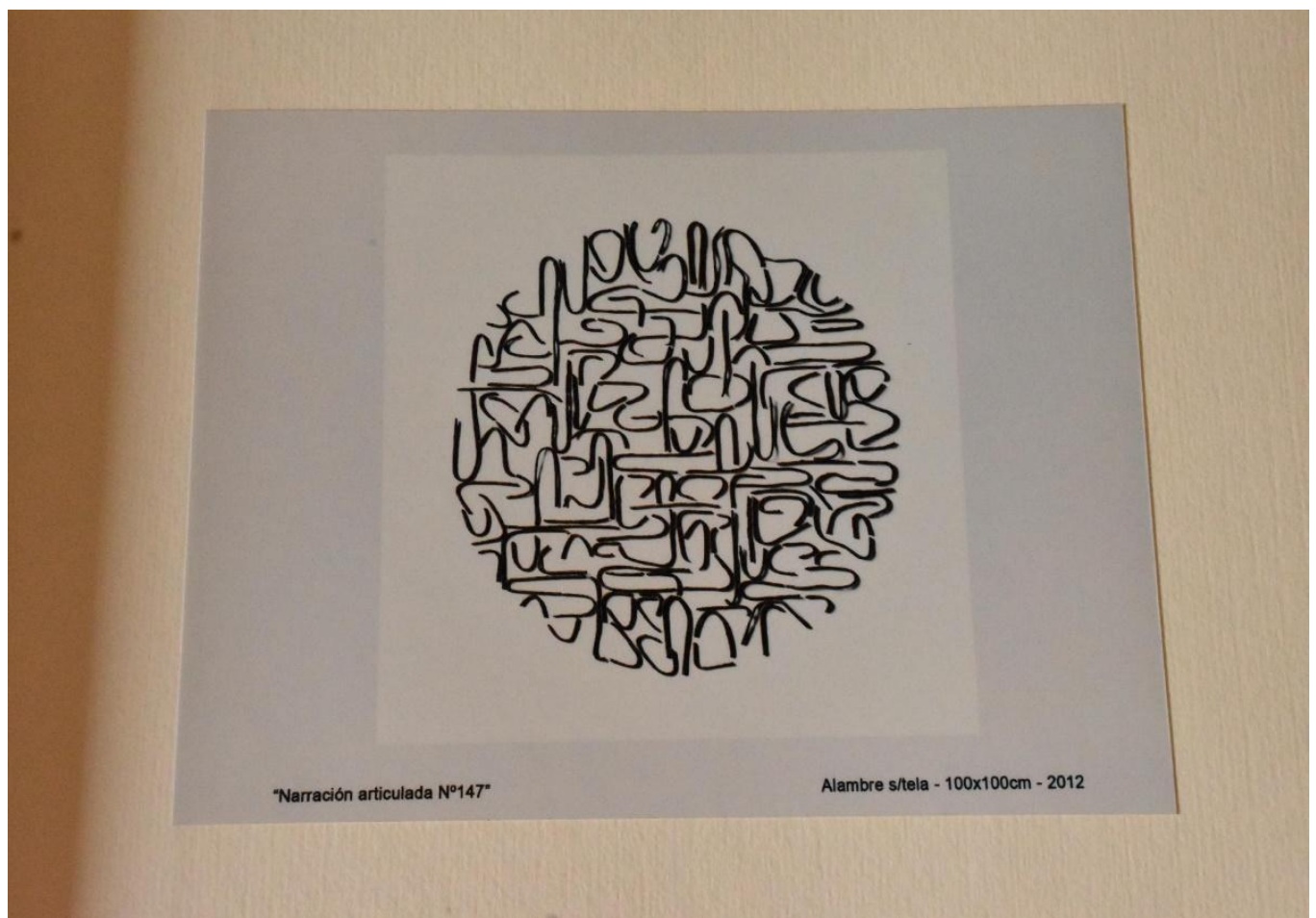

Figura 9. "Narración articulada $N^{\circ}$ 147". Alambre sobre tela-100x100 com. Autora de la obra: Mercedes Resch.

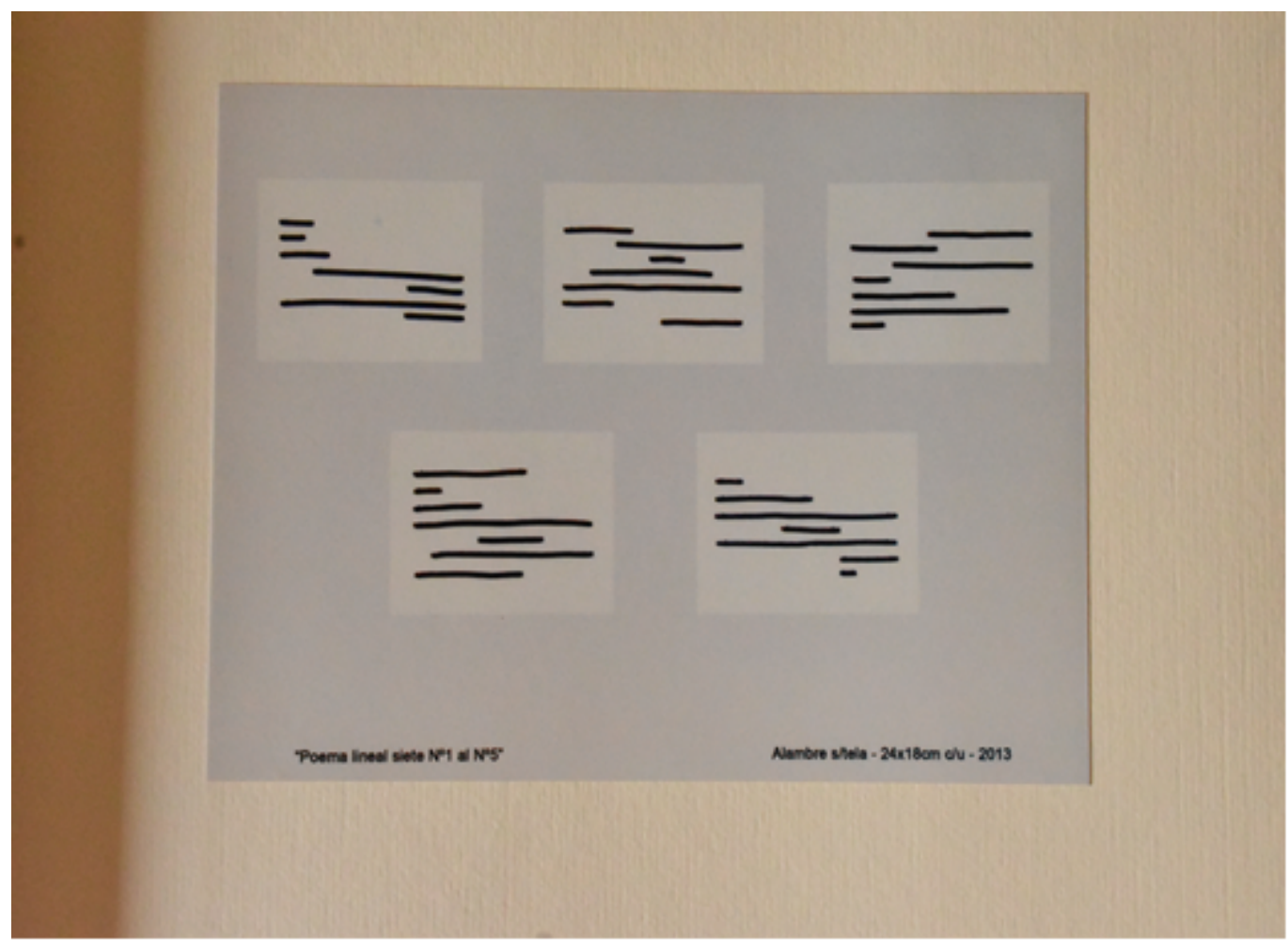

Figura 10. "Poema lineal siete $\mathrm{N}^{\circ} 1$ al $\mathrm{N}^{\circ} 5$ ". Alambre sobre tela- $24 \times 18 \mathrm{~cm}$. Autora de la obra: Mercedes Resch. 


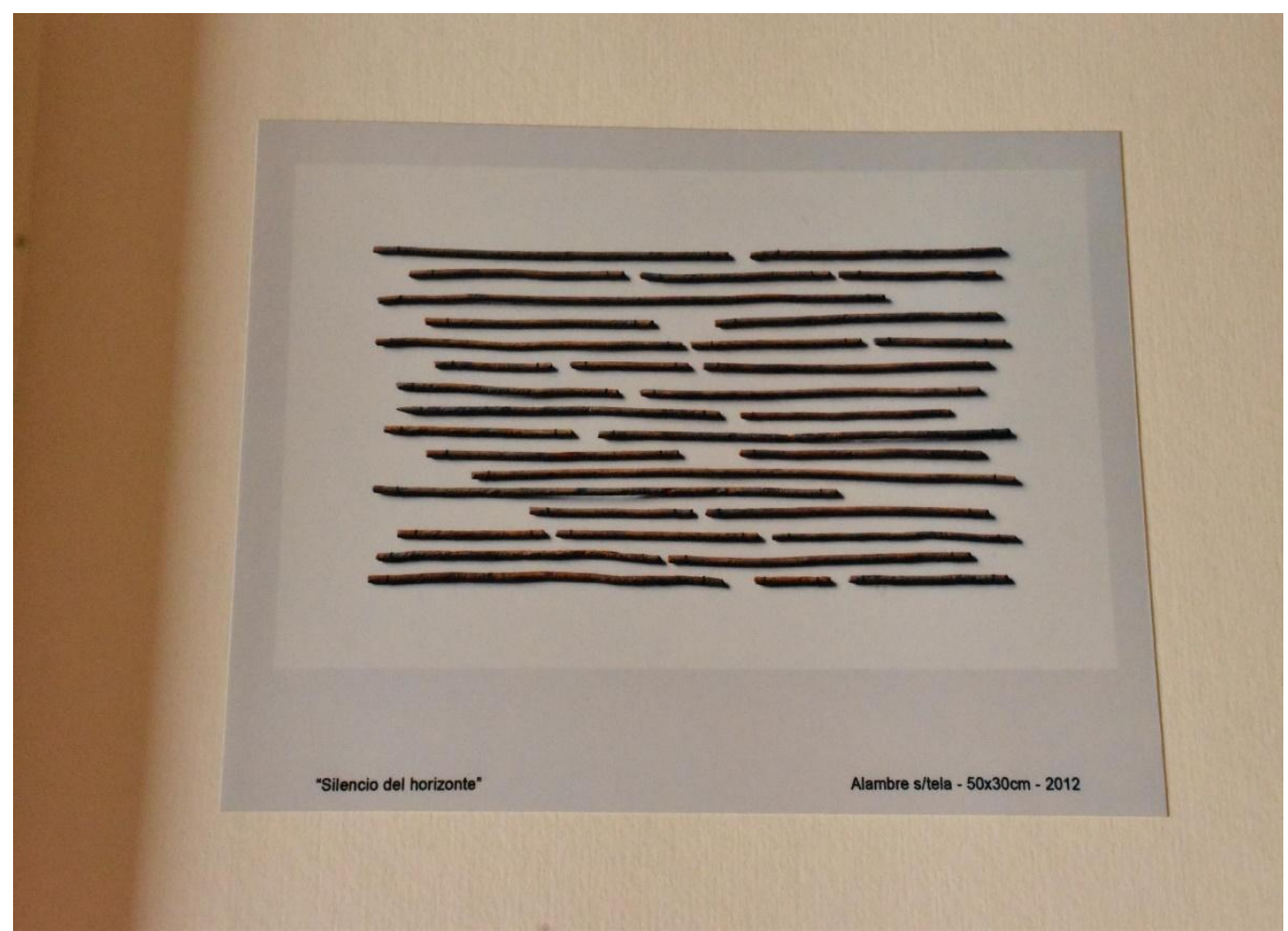

Figura 11. "Silencio de los pastizales". Alambre sobre tela- 50x30. Autora de la obra: Mercedes Resch. ${ }^{9}$

\footnotetext{
${ }^{9}$ La edición artesanal de los registros fotográficos de las muestras y de los procesos creativos de la obra es realizada también por la autora y se encuentra disponible para su visualización en el espacio de arte "La Tranca" de Cura Malal. Las fotos que aquí se comparten fueron sacadas durante la visita al lugar y cuentan con el permiso de Mercedes Resch para su utilización en este trabajo.
} 


\section{Conclusiones}

"No pertenecer a algo duradero es la peor de las agonías".10

Las acciones artísticas desarrolladas en Cura Malal e impulsadas por Proyecto Hermosura, junto con la obra producida por la artista Mercedes Resch, nos permitieron ver, en primer lugar, de qué manera la apuesta de nuestros estudios críticos por objetos, prácticas y acontecimientos más silenciosos o más invisibles ante los oídos y ojos de los grandes centros urbanos, diseñados durante el paradigmático proceso de modernización nacional, impacta no sólo sobre las nociones de arte, literatura y archivo en este caso, es decir su dimensión teórica, ${ }^{11}$ sino también, y esto es lo que en este artículo interesó destacar, sobre la posibilidad de recuperación y preservación de un paisaje y comunidad amenazados por las progresivas políticas de planificación territorial y privatización económica (Gorelik, 2004), caracterizadas principalmente en la zona por el creciente avance del alambrado sobre los campos, el aislamiento poblacional y un proceso particular de "despaisamiento". Es en la mirada puesta en la pequeñez y fragilidad de nuestros objetos de estudio donde parece radicar una posible estrategia de resistencia ante un orden de pensamiento y diagrama político construido sobre una solidez que, paradójicamente, pone en ruinas nuestros saberes emancipatorios y nuestros ecosistemas regionales (López, 2010). Al mismo tiempo, tal vez dicha mirada puesta sobre lo nimio y lo que amenaza en desaparecer del plan modernizador nos permita recordar, con mayor proximidad, que antes que las grandes naciones que el proceso ha logrado instaurar fuimos y somos comunidades (Rivera Cusicanqui, 2018). Baste traer nuevamente ante nuestros ojos las cartografías a mano alzada hechas por los habitantes de Cura Malal o el poema visual y sonoro producido también por ellos bajo la consigna de escucha y escritura del Proyecto Hermosura. Allí, leíamos los elementos que forman parte del paisaje del lugar: animales, aves, vegetación, insectos, una mujer, un hombre, un auto y un tren que pasa. Todos estos fueron identificados por sus habitantes con un grado de conocimiento y proximidad tal que con el tan solo acto de la escucha-y sin utilizar como medio el régimen dominante del ojo (Jay, 2008) - pudieron clasificarlos con nombres y ubicaciones específicas: una paloma torcaza, un zorro de agua, la vaca de Raimunda, un camino vecinal, etc. La producción del poema permitió, de este modo, poner en evidencia un sentido de "comunidad de afinidades" y no sólo de parentescos (Rivera Cusicanqui, 2015) entre los sujetos y también entre ellos y el entorno natural que habita en ese territorio. Esto se hace visible y audible en el poema mediante el diálogo cotidiano que allí se suscita con el paisaje y mediante el reconocimiento espacial de agentes humanos y no humanos (máquinas y pasos de seres humanos, un arroyo, aves y mamíferos, ramas secas, barro) en permanente convivencia, roce y también

\footnotetext{
10 Dicha frase se encuentra grabada, al igual que la que acompaña, también como epígrafe, la introducción de este artículo, en una de las mesas de la pulpería y espacio de arte "La Tranca".

${ }^{11}$ Me refiero a cómo impactan estos proyectos colectivos e intervenciones culturales en nociones centrales de la teoría artística y literaria, tales como la de "representación", "obra”, "autor", "firma”, "circulación", "recepción", "reproductibilidad", "archivo", etc. Este trabajo no se centró en estas nociones sino en las que en las conclusiones se mencionan con otra especificidad.
} 
conflicto. Porque el sentido de comunidad que el arte y la poesía colectiva de Cura Malal devuelve a nuestros ojos y oídos no es sólo de humanos y el ensamble entre esas distintas dimensiones que allí se reconstruyen permite hacer entrar en crisis tanto los modos de vida actuales, como los modos hegemónicos de contemplarla y ponerla en escena (Rivera Cusicanqui, 2015, 146-147).

Por otro lado, hemos visto aparecer con la producción artística de Mercedes Resch, "Silencio de los pastizales", un paisaje visual y háptico capaz de devolver ante nuestros ojos y nuestras manos la materialidad de un porvenir en que los alambres ya no interrumpen la infinitud de nuestra experiencia perceptiva en el campo, sino más bien la expanden y diseñan, al igual que los mapeos realizados por la comunidad de Cura Malal, otras líneas de fuga con formas circulares y poéticas capaces de recorrer el paisaje y habitarlo.

De este modo, es a partir del arte y las cartografías poéticas de todas las hermosuras de Cura Malal que es posible recuperar una experiencia y una noción de comunidad que las insistentes políticas económicas a lo largo de la historia nacional han intentado disolver, así como también es posible recuperar una experiencia y una noción del paisaje rural-serrano de Cura Malal como ensamble con la comunidad, y no como un mero escenario o decorado costumbrista al que la literatura argentina ha solido mostrarnos a través de la imagen del desierto, el ombú y el gaucho a caballo (Díaz, 2008). En términos de Jens Andermann, una idea de paisaje capaz de dar cuenta, inclusive, de su propia posición intersticial y oscilante entre imagen y entorno, como aquello que ensambla la construcción perceptiva de los sujetos con los efectos que ésta produce en la materialidad de lo que abarca (Anderman, 2008, 6).

Finalmente, la mirada puesta sobre la potencia del archivo vivo que las acciones artísticas y colectivas desarrolladas en el territorio de Cura Malal construyen, recupera la importancia de las supervivencias en nuestro permanente presente en crisis, así como también, en un doble movimiento y efecto, preservan a esas tierras de otro remate y a la comunidad de una agónica desaparición. Que el corral de piedras que las sierras montan sobre la llanura bonaerense continúe siendo una fortaleza duradera en el paisaje y que nuestros ojos no dejen de mirarlas y mostrarlas, también, con sentido histórico, crítico y poético. Ese será, además de su preservación ecológica, un resguardo del paisaje en el tiempo. 


\section{Referencias}

AA.VV. (2010). Vías argentinas. Ensayos sobre el Ferrocarril. Buenos Aires, Argentina: Milena Caserola.

Andermann, J. (2008). “Paisaje: imagen, entorno, ensamble”. En Orbis Tertius, 13 (14). Recuperado de: http://www.memoria.fahce.unlp.edu.ar/art_revistas/pr.3749/pr.3749.pdf

Antelo, R. 2015. Archifilologías latinoamericanas. Lecturas tras el agotamiento. Villa María, Argentina: Eduvim.

Benjamin, W. (1992). Desenterrar y recordar. En Cuadros de un pensamiento (pp. 118-119). Buenos Aires, Argentina: Imago Mundi. Selección, cronología y postfacio de Adriana Mancini. Traducción de Susana Mayer con la colaboración de A. Mancini.

Bocchino, A. (2010). El yo inevitable. La experiencia de sí en Walter Benjamin. En Actas del II Coloquio Internacional. Escrituras del yo (pp. 1-17). Rosario, Argentina: Centro de Estudios de Teoría y Crítica Literaria. Centros de Estudios de Literatura Argentina. FHyA-UNR. Recuperado de: file://C:/Users/maria/Desktop/TESIS/Textos\%20para\%20la\%20tesis/bo cchino benjamin.pdf

Canal-Feijóo, B. (1934). El asalto a la selva. Ñan-Revista de Santiago 2, pp.60-76.

Deleuze, G. y Guattari, F. (1997[1976]). Introducción: Rizoma. Mil mesetas. Capitalismo y esquizofrenia (pp.9-32). Madrid, España: Pretextos.

Derrida, J. (2013). Archivo y borrador. En G. Goldchluk, y M. Pené (Comp.). Palabras de archivo (pp.205-233). Santa Fe, Argentina-Poitiers, Francia: Ediciones UNL-CRLA Archivos.

Díaz, M. (2008). Piezas sueltas para un rompecabezas pampeano. En M. Resch, N. Rosemberg y V. Suanno. Proyecto Hermosura (s/p). Coronel Suárez, Argentina: Publicación autogestiva y abierta.

Didi-Huberman, G. (2007). Das Archiv brennt. En G. Huberman-Didí y K. Ebeling (Eds.), Das Archiv brennt (pp. 7-32). Berlín, Alemania: Kadmos; Traducción a cargo de Juan Ennis para la cátedra de Filología Hispánica UNLP. Recuperado de: https://filologiaunlp.files.wordpress.com/2012/05/el-archivo-arde1.pdf.

Dos Santos, H. (2004). 120 años: 1882-2002 en la historia de Coronel Suárez. Tomo III. Buenos Aires, Argentina: Talleres Gráficos.

Fernández López, M. (1974). Los nuevos dueños del desierto. En AA.VV. Las bases de la expansión (pp.92-103). Buenos Aires, Argentina: Centro Editor de América Latina. 
Gache, B. (2013). Armando rompecabezas de tiempo y de silencios. Texto curatorial escrito para la muestra de la obra visual de Mercedes Resch, Silencio de los pastizales. Barraca Vorticista, Buenos Aires, Argentina.

Gerbaudo, A. (2013). Archivos, literatura y políticas de exhumación. En G. Goldchluk y M. Pené (Comp.). Palabras de archivo (pp.57-87). Santa Fe, Argentina-Poitiers, Francia: Ediciones UNL-CRLA ARCHIVOS.

Goldchluk, G. y Pené, M. (2013) Introducciones para archivar un pájaro. Introducción. En G. Goldchluk y M. Pené (Comp.). Palabras de archivo (pp.5-13). Santa Fe, Argentina-Poitiers, Francia: Ediciones UNL-CRLA ARCHIVOS.

Gorelik, A. (2004). Miradas sobre Buenos Aires. Historia cultural y crítica urbana. Buenos Aires, Argentina: Siglo XXI.

Jay, M. (2008). Ojos abatidos. Madrid, España: Akal. Traducción a cargo de Francisco López Martín.

Lenton, D.; Delrio, W.; Pérez, P.; Papazian, A.; Nagy M. y Musante, M. (2015). Huellas de un genocidio silenciado: los indígenas en Argentina. Revista Conceptos, 90 (493), pp. 219-242. Recuperado de:

https://ri.conicet.gov.ar/bitstream/handle/11336/52773/L-0587-120-143 .pdf? sequence $=5 \&$ is Allowed $=y$

Lobato, M. Z. (Dir.) (2000). Nueva historia argentina. El progreso, la modernización y sus límites (1880-196). Tomo V. Buenos Aires, Argentina: Sudamericana.

López, M. P. (2010). Vías cruzadas. En AA.VV. Vías argentinas. Ensayos sobre el Ferrocarril (pp.25-37). Buenos Aires, Argentina: Milena Caserola.

Millone, G. (2017). Escribir la voz. El jardín de los poetas. Revista de teoría y crítica de poesía latinoamericana, 3 (4), pp.49-57. Recuperado de: file:///C:/Users/maria/Downloads/Escribir_la_voz.pdf

Pedrotta, V. (2011). A diez años del inicio del proyecto de investigación arqueológica sobre los "corrales de piedra" de Tandilia. En Newsletter $\mathrm{N}^{\circ} 19$. Recuperado de: https://www.soc.unicen.edu.ar/index.php/newsletter/87-newsletter/n19/ 293--a-diez-anos-del-inicio-del-proyecto-de-investigacion-arqueologica-sob re-los-corrales-de-piedra-de-tandilia

Rasic, M. E, Resch, M., Rosemberg, N. y Suanno, V. (2019). Arte y poesía sobre los rieles del archivo. Un ramal que conecta territorios y comunidades. El taco en la brea, 6 (10), pp.150-160. Dossier "Comunidades". Santa Fe, Argentina: UNL. Recuperado de: https://bibliotecavirtual.unl.edu.ar/publicaciones/index.php/ElTacoenlaBr ea/article/view/8695/12343. 
Resch, M., Rosemberg, N., Suanno, V. (2008). Proyecto Hermosura. Coronel Suárez, Argentina: Publicación autogestiva y abierta.

Resch, M. (2012-2013). El silencio de los pastizales. Obra visual Cura Malal, Argentina: Edición artesanal y autogestiva.

Rodríguez, S. (2008 [1908]). “Pueblo Curamalán”. En M. Resch, N. Rosemberg y V. Suanno. Proyecto Hermosura (s/p). Coronel Suárez, Argentina: Publicación autogestiva y abierta.

Rivera Cusicanqui, S. (2015). Sobre la comunidad de afinidad y otras reflexiones para hacernos y pensarnos en un mundo otro. El Aplante. Revista de estudios comunitarios (1), pp.141-169. Número especial “Común, ¿para qué?”. Puebla, México: Sociedad Comunitaria de Estudios Estratégicos.

Rivera Cusicanqui, S. (2018). Un mundo ch'ixi es posible. Ensayos desde un presente en crisis. Buenos Aires, Argentina: Tinta Limón.

Viñuales, G. M. (2010). Los poblados de la explotación forestal. En AA.VV Vías argentinas. Ensayos sobre el Ferrocarril. Buenos Aires, Argentina: Milena Caserola.

\section{Sitios web de referencia utilizados:}

"Proyecto Hermosura". Blog. Recuperado de: http://proyectohermosura.blogspot.com/

“La Tranca Cura Malal. Espacio de arte". Recuperado de Facebook. 